\title{
Synthesis of PLLA-b-PCL-b-PLLA linear tri-block copolymers and their corresponding poly(ester-urethane)s: effect of the molecular weight on their crystallisation and mechanical properties
}

\author{
Ivan Navarro-Baena, ${ }^{a}$ Angel Marcos-Fernández, ${ }^{b}$ Alberto Fernández-Torres, ${ }^{b}$ José M. Kenny $^{a, b}$ and \\ ${ }_{5}$ Laura Peponi* ${ }^{b}$
}

With the general objective to design polymer based materials with specific thermal and mechanical properties, a systematic study on the crystallinity and the mechanical properties of synthesized linear tri-block copolymers based on poly(L-lactic acid) and poly( $\varepsilon$ 10 caprolactone) and of their corresponding poly(ester-urethane)s has been performed. In particular, eleven tri-block copolymers were synthesized varying both the molecular weight of the blocks as well as the relative content of each block in the copolymer, focusing the attention on the relationship between their chemical compositions and their tailored final properties in order to tune them taking into account their possible applications (i.e. as shape memory materials). From them, eleven poly(ester-urethane)s were synthesized by condensation with hexamethylene diisocyanate (HDI). The chemical composition of the synthesized polymers was studied and correlated 15 with their thermal and crystalline properties obtained by both dynamic scanning calorimetry (DSC) and small angle X-ray diffraction (SAXS) experiments. The relationship between their crystalline structure, thermal and mechanical properties with the molecular weight as well as with the relative content of each comonomer in the copolymers and the amount of HDI in the poly(ester-urethane) was analysed. The results obtained demonstrate that these bio tri-block copolymers and the corresponding poly(ester-urethane)s can be tailored with interesting crystalline and mechanical properties. Future applications as shape memory systems are thus envisaged.

20

${ }^{a}$ University of Perugia, Strada di Pentima 4, Terni, Italia.

${ }^{b}$ Institute of Polymer Science and Technology (ICTP-CSIC), Calle Juán de la Cierva 3, Madrid, Spain.

*Correspondence to: Laura Peponi (E-mail: lpeponi@ictp.csic.es)

\section{Introduction}

The development and use of biopolymers have increased in recent years due to their versatility and their unique properties well-adaptable to the innovative applications requested in bio-

30 medicine and other advanced fields. In this context, aliphatic polyesters such as poly(L-lactic acid) (PLLA), poly( $\varepsilon$ caprolactone) (PCL) or poly(glycolic acid) (PGA) are interesting polymers for several bio-applications. ${ }^{1-4}$ These polymers are biocompatible and they degrade through hydrolytic scission of 35 the ester groups, thus being suitable for biomedical applications such as scaffolds for tissue engineering, drug delivery systems or sutures among others..$^{5-7}$ In the last years copolymers and blends of these homopolymers have been studied in order to design new materials with specific properties in which their synergetic effect 40 could be exploited. ${ }^{8-11}$ At this regard, it is important to consider not only their synergetic interaction but also how this interaction can influence their final properties in to design specific materials with tailored specific properties.

PLLA, obtainable from renewable sources, is a rigid polymer 45 having a glass transition temperature $\left(\mathrm{T}_{\mathrm{g}}\right)$ around $60{ }^{\circ} \mathrm{C}$. It melts around $180{ }^{\circ} \mathrm{C}$ and shows good mechanical properties. Nowadays PLLA is mainly used in packaging applications, ${ }^{12}$ replacing polymers derived from no-renewable sources but its main drawback is its brittleness. ${ }^{8}$ On the other hand, PCL is a flexible ${ }_{50}$ polymer with a melting temperature $\left(\mathrm{T}_{\mathrm{m}}\right)$ around $60{ }^{\circ} \mathrm{C}$ and a $\mathrm{T}_{\mathrm{g}}$ at $-60{ }^{\circ} \mathrm{C}$. In order to enhance their mechanical, thermal or biodegradability properties, the preparation of synergistic blends and different di-, tri-, multi-block and random copolymers based on PCL and PLLA have been reported recently on the scientific 55 literature. ${ }^{13-18}$ In particular, Castillo et al. ${ }^{13}$ and Peponi et al. ${ }^{14}$ reported the influence of the composition of di-block copolymers of PCL and PLLA on their thermal properties. In those research works, the melting temperature and the crystallinity of each block were related to the chain length. Furthermore Fernandez et al. ${ }^{15}$ 60 reported the synthesis of statistical copolymers of PCL and PLLA, and they found variations on thermal as well as on mechanical properties related to the chemical composition. Cohn et al. $^{16}$ reported thermoplastic elastomers based on PCL and PLLA with a block structure which showed a wide range of 65 values in terms of mechanical properties and biodegradability depending on their chemical composition. Vilay et al. ${ }^{17}$ studied blends of PCL and PLLA and reported the poor miscibility of the homopolymers. In their research they improved the miscibility of the system using a tri-block copolymer based on poly(ethylene 70 oxide) and poly(propylene oxide) as compatibilizer. Lu et al. ${ }^{18}$ studied the effect of the composition on the shape memory behaviour of statistical copolymers based on PCL and PLLA. The shape memory behaviour was investigated in terms of shape recovery rate and recovery stress. They found that the addition of 75 PCL at low concentrations enhanced the shape memory parameters at different strain rates. Also Peponi et al. ${ }^{19}$ synthesized a poly(ester-urethane) based on PCL-PLLA block copolymers with shape memory behaviour with a transition temperature of about $40^{\circ} \mathrm{C}$ for deformations up to $350 \%$.

80 In the research reported here the attention has been focused on the synthesis and the characterization of PLLA-b-PCL-b-PLLA triblock copolymers and of their corresponding poly(esterurethane)s, analysing the effects of their molecular weight and of their composition on the crystallisation behaviour of the 85 synthesized polymers. The mechanical properties of the synthesized poly(ester-urethane)s were also investigated and 
related to their crystalline structure. This correlation is very important due to the necessity to design new materials with specific properties, where not only the ratio between the different blocks is relevant but also their thermo-mechanical response, ${ }_{5}$ such as in designing materials with shape memory behaviour. ${ }^{19}$ Eleven tri-block copolymers based on PCL and PLLA have been synthesized, varying both the ratio of the two blocks and the molecular weight of each block. After that, eleven poly(esterurethane)s have been synthesized through the reaction of these 10 copolymers with hexamethylene diisocyanate (HDI). The molecular weight of the tri-blocks was studied with nuclear magnetic resonance $\left({ }^{1} \mathrm{H}\right.$ NMR) and matrix-assisted laser desorption/ionization time-of-flight (MALDI-TOF) experiments. To confirm the reaction of the hydroxyl groups of the tri-block 15 copolymers with the isocyanate groups of the HDI, ${ }^{1} \mathrm{H}$ NMR and Fourier transform infrared spectroscopy (FT-IR) measurements were performed. The amorphous/crystalline nature of all polymers was studied by Small Angle X-Ray Scattering (SAXS) experiments and Differential Scanning Calorimetry (DSC). The 20 mechanical properties were investigated using standard tensile tests.

\section{Experimental}

\section{Materials}

L-lactide (L-LA), HDI, stannous octoate $\left(\mathrm{Sn}(\mathrm{Oct})_{2}\right)$, chloroform, 25 methanol and dichloroethane were purchased from Sigma Aldrich (Spain). Three different commercial PCL diols, with different nominal molecular weights (2000, 4000 and $8000 \mathrm{~g} / \mathrm{mol}$ ), donated by Perstorp (Sweden), were used. All the materials employed in this work were used as received without further 30 purification.

\section{Synthesis of PLLA-b-PCL-b-PLLA tri-block copolymers}

Eleven different tri-block copolymers were synthesized by ring opening polymerization of L-lactide by the hydroxyl-end groups of the PCL diol in the presence of $\mathrm{Sn}(\mathrm{Oct})_{2}$ as catalyst (Scheme 35 1). The amount of L-lactide and PCL diol was calculated in order to obtain 5 grams of final product; $\mathrm{Sn}(\mathrm{Oct})_{2}$ was added in 0.1 wt\% respect to the L-lactide monomer. The reaction was carried out in bulk, in a $15 \mathrm{ml}$ round bottom flask immersed in an oil bath at $180{ }^{\circ} \mathrm{C}$ for $3 \mathrm{~h}$. After that, when the temperature decreased, the 40 mixture was dissolved in chloroform and precipitated in cold methanol. The white precipitate was filtered off and dried under vacuum to extract all residual solvents. The synthesized tri-block copolymers are named with the prefix T-. Their composition in terms of block molecular weight and weight ratio between the ${ }_{45}$ blocks are reported in Table 1.

\section{Synthesis of poly(ester-urethane)s based on PCL-PLLA}

Starting from the synthesized tri-block copolymers, a polycondensation reaction with hexamethylene diisocyanate 50 (HDI) at 1:1 molar ratio was carried out taking advantage of the presence of the hydroxyl groups at the ends of the tri-blocks chains. This reaction linked the tri-blocks through urethane bonds thus forming a poly(ester-urethane) and was performed in a $25 \mathrm{ml}$ round bottom flask using dichloroethane as solvent and $\mathrm{Sn}(\mathrm{Oct})_{2}$
55 as catalyst, at $80{ }^{\circ} \mathrm{C}$ for 5 hours. The initial molar concentration of the tri-blocks was around $0.1 \mathrm{~mol} / \mathrm{l}$. Once the reaction finished, the product was diluted with chloroform and the solution casted onto a leveled glass. The films were dried at ambient conditions for 12 hours and then under vacuum at room temperature for at ${ }_{60}$ least 24 hours to remove the residual solvent. The obtained poly(ester-urethane)s are named with the prefix PU-, following the same order of the corresponding previously synthesized triblock materials.

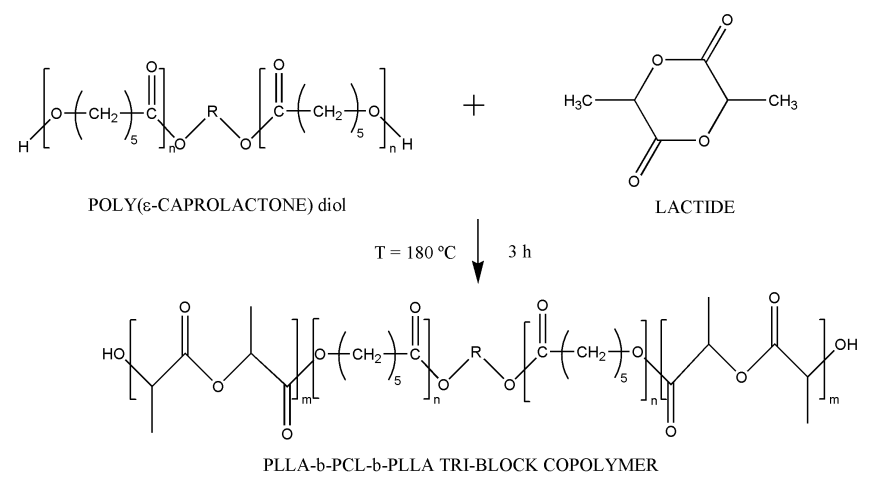

${ }_{65}$ Scheme 1. Synthesis procedure of tri-block copolymers.

Table 1. Main chemical structure characteristics of the synthesized tri-block copolymers.

\begin{tabular}{|c|c|c|c|c|c|}
\hline $\begin{array}{c}\text { Samp } \\
\text { le }\end{array}$ & $\begin{array}{c}\text { CL:L } \\
\mathrm{A}^{1}\end{array}$ & $\begin{array}{c}\text { CL:L } \\
\mathrm{A}^{2}\end{array}$ & $\begin{array}{c}\mathrm{M}_{\mathrm{n}, \mathrm{PC}} \mathrm{L}^{3} \\
(\mathrm{~g} / \mathrm{mo} \\
\mathrm{l})\end{array}$ & $\begin{array}{c}\mathrm{M}_{\mathrm{n}} \\
\text { tribloc } \\
\mathrm{k}^{2} \\
(\mathrm{~g} / \mathrm{mol} \\
)\end{array}$ & $\begin{array}{c}\mathrm{M}_{\mathrm{n}} \\
\text { tribloc } \\
\mathrm{k}^{4} \\
(\mathrm{~g} / \mathrm{mol} \\
)\end{array}$ \\
\hline T1 & $85: 15$ & $92: 08$ & 8049 & 8735 & 8840 \\
\hline T2 & $70: 30$ & $89: 11$ & 2054 & 2306 & 2562 \\
\hline T3 & $70: 30$ & $84: 16$ & 4021 & 4808 & 4937 \\
\hline T4 & $70: 30$ & $77: 23$ & 8049 & 10393 & 10286 \\
\hline T5 & $50: 50$ & $73: 37$ & 2054 & 2903 & 3152 \\
\hline T6 & $50: 50$ & $54: 46$ & 4021 & 7375 & 7266 \\
\hline T7 & $50: 50$ & $54: 46$ & 8049 & 15022 & 13670 \\
\hline T8 & $30: 70$ & $34: 66$ & 2054 & 6056 & 5756 \\
\hline T9 & $30: 70$ & $33: 67$ & 8049 & 24608 & 19410 \\
\hline T10 & $30: 70$ & $32: 68$ & 4021 & 12502 & 10316 \\
\hline T11 & $15: 85$ & $18: 82$ & 8049 & 45375 & 28335 \\
\hline
\end{tabular}

70 1Feed weight ratio. 2Calculated by $1 \mathrm{H}$ NMR using CL/LA ratio. 3 Determined from the hydroxyl value. 4Calculated by $1 \mathrm{H}$ NMR using LA end groups.

\section{Characterization}

75 Solution ${ }^{1} \mathrm{H}$ NMR spectra were recorded at room temperature in a Varian Unity Plus 400 instrument using deuterated chloroform $\left(\mathrm{CDCl}_{3}\right)$ as solvent. Spectra were referenced to the residual 
solvent protons at $7.26 \mathrm{ppm}$.

Fourier transform infrared (FT-IR) spectra were performed in a Perkin Elmer Spectrum One FT-IR spectrometer equipped with an ATR accessory. Spectra were taken in the range $650-4000 \mathrm{~cm}^{-}$

${ }_{5}^{1}$ with a resolution of $1 \mathrm{~cm}^{-1}$ and an accumulation of 16 scans. Differential scanning calorimetry (DSC) analysis was performed in a Mettler Toledo DSC822e instrument. Samples of about 10 $\mathrm{mg}$ were sealed in aluminum pans. Thermal cycles consisted of two heating scans (from 0 to $200{ }^{\circ} \mathrm{C}$ and from -90 to $200{ }^{\circ} \mathrm{C}$ ) and 10 a cooling scan (from 200 to $-90{ }^{\circ} \mathrm{C}$ ) in between them, at a heating/cooling rate of $10{ }^{\circ} \mathrm{C} / \mathrm{min}$ under nitrogen purge. The values of $\mathrm{T}_{\mathrm{m}}$ were obtained as the maximum of the endothermic peak and the enthalpy of melting $\left(\Delta \mathrm{H}_{\mathrm{m}}\right)$ was calculated as the integral of the area below the peaks. Data reported here were 15 taken from the second heating scan.

SAXS measurements of both tri-block copolymers and poly(ester-urethane)s were taken at beamline BM16 at the European Synchrotron Radiation Facility (Grenoble, France). Triblocks were melted and sealed in DSC aluminum pans, placed 20 within a Linkam hot stage and heated at $10{ }^{\circ} \mathrm{C} / \mathrm{min}$ while the SAXS spectra were recorded. Poly(ester-urethane) samples have were wrapped in aluminum foils without any thermal treatments before carrying out the SAXS experiments. Temperature calibration gave a difference of approximately $7{ }^{\circ} \mathrm{C}$ between the 25 temperature reading at the hot stage display and the real temperature at the sample. Detector calibration was performed with silver behenate $\left(\mathrm{AgC}_{22} \mathrm{H}_{43} \mathrm{O}_{2}\right)$. The long period $\mathrm{L}$ was calculated as $2 \pi / \mathrm{q}$, where $\mathrm{q}$ is the scattering vector.

Tensile properties were measured in a MTS Synergie 200 testing 30 machine equipped with a $100 \mathrm{~N}$ load cell. Type 3 dumbbell test specimens (according to ISO 37) were cut from film. A crosshead speed of $200 \mathrm{~mm} / \mathrm{min}$ was used. Strain was measured from crosshead separation and referred to $10 \mathrm{~mm}$ initial length. Five samples were tested for each poly(ester-urethane).

35

\section{Results and discussion}

\section{Synthesis of tri-block copolymers}

Eleven different PLLA-b-PCL-b-PLLA tri-block copolymers have been synthesized varying both the relative content as well as 40 the molecular weight of each block in the copolymer. Three different commercial PCL diols were selected having nominal molecular weights of about 2000, 4000 and $8000 \mathrm{~g} / \mathrm{mol}$. The real molecular weights of these materials were calculated from the hydroxyl value provided in the data sheet and are reported in

${ }_{45}$ Table 1 . The theoretical PCL:PLLA weight ratios selected were 15:85, 30:70, 50:50, 70:30 and 85:15. All synthesized copolymers were analysed by ${ }^{1} \mathrm{H}$ NMR spectroscopy. The real weight ratios as well as the molecular weights calculated by ${ }^{1} \mathrm{H}$ NMR analysis for the eleven tri-block copolymers synthesized are summarized 50 in Table 1.

The analysis of ${ }^{1} \mathrm{H}$ NMR spectra was performed taking into account the work of Kaspercyk. ${ }^{20}$ In Fig. 1 the spectrum for T6 is shown (for the other tri-block copolymers the spectra are not reported, but they were similar to the one reported in Fig. 1). The 55 multiplet at $5.05-5.25 \mathrm{ppm}$ and the multiplet at $4.35 \mathrm{ppm}$ correspond to the methine proton $f$ of polymerized lactide and to the methine proton of lactide end group $f$ respectively. The signal of un-reacted L-lactide in the final products, peak at 5.03 ppm, was less than $1 \mathrm{wt} \%$ for all samples. The triplet at 4.05 ${ }_{60} \mathrm{ppm}$ corresponds to protons $a$ and it is related to CL units linked to another CL unit and to the CL units linked to the LA units. The triplet at 2.30 corresponds to the protons $e$ of CL linked to another CL unit. The other signals correspond to CL protons $b, d$ and $c$ at $1.66,1.63$ and $1.37 \mathrm{ppm}$ respectively and the multiplet at ${ }_{65} 1.57 \mathrm{ppm}$ corresponds to the LA methyl proton $\mathrm{g}$, while the peak at $1.49 \mathrm{ppm}$ corresponds to the end group of LA methyl proton $g$ '. Two main aspects can be underlined: signals of residual solvents were not present and no signal of CL terminal groups appeared, at about $3.74 \mathrm{ppm}$, so the desired molecular structure 70 with PCL midblock (PLLA-b-PCL-b-PLLA) was confirmed.

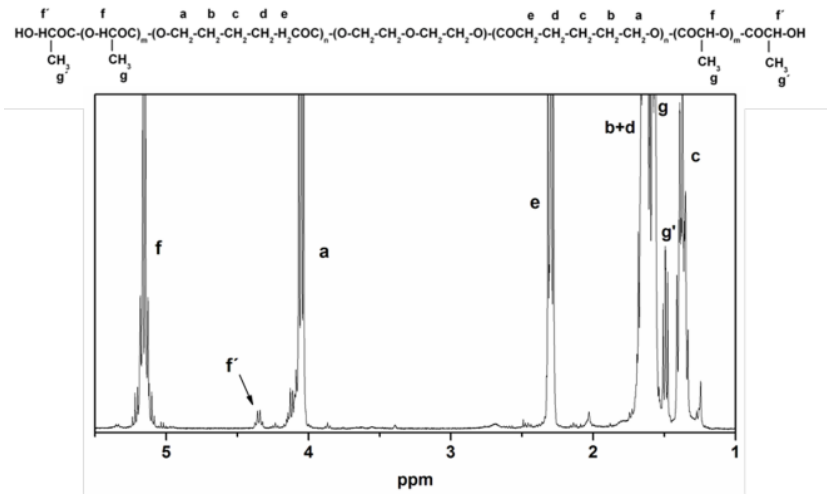

Fig. $1 .{ }^{1} \mathrm{H}$ NMR spectrum of T6.

In order to determine the molecular weight of the copolymers two 75 methods have been used. In the first one, the ratio between the signals for the PCL and the PLLA units is used. The selected signals for calculation are the protons $f+f$ ' for the PLLA units and the protons $a$ for the PCL units. In the second method, the ratio between the signal for PLLA ester units $f$ and the signal for PLLA 80 end group, $f^{\prime}$ has been used. The molecular weight for the triblocks calculated by both methods is reported in Table 1 . It can be observed that the agreement in the values calculated by both methods is good, with a difference of approximately $10 \%$ or less except for the longer copolymers (above $10.000 \mathrm{~g} / \mathrm{mol}$ ). For the 85 latter, the larger difference can be attributed to a higher error in the calculation of $f$ ' signal when the molecular weight increases. For this reason, the first method was considered as more precise, and the molecular weight for the copolymer was taken as the value calculated from the ratio between PCL and PLLA signals. 90 The molecular weight distribution was investigated by MALDITOF and GPC experiments (data not-shown). The values of polydispersity of the different synthesized copolymers ranged from 1.2 to 1.5 .

The main characteristic peaks corresponding to the PCL and the ${ }_{95}$ PLLA blocks have been studied by FT-IR analysis. In general, the intensity of the peaks is related to the polymer composition; however, in our case it is difficult to quantify the chemical composition with this technique, thus FT-IR analysis is qualitative. In Fig. 2 the carbonyl stretching region of the FT-IR 100 spectra for the synthesized tri-block copolymers is represented. This figure is divided into three graphs depending on the nominal molecular weight of the starting PCL diol, that is 2000, 4000, 
$8000 \mathrm{~g} / \mathrm{mol}$. Moreover, the percentages of PCL are reported in the graphs in order to facilitate the lecture of the diagrams. The more intense peaks in the carbonyl stretching region of $1800-1650 \mathrm{~cm}^{-1}$ correspond to both ester units (at about $1756 \mathrm{~cm}^{-1}$ for PLLA and $51721 \mathrm{~cm}^{-1}$ for PCL). The peaks in the region of $600-1200 \mathrm{~cm}^{-1}$ correspond to characteristic vibration modes of PCL and PLLA as it is detailed in literature. ${ }^{21,22}$ The variation on the peak intensities with the polymer composition is evidenced. The polymers with high content of PCL, such as T1, T2 and T3, 10 corresponding to the first line of each diagram, respectively, show a strong peak at $1721 \mathrm{~cm}^{-1}$, while for the polymers having intermediate compositions, this peak appears with less intensity and the peak at $1756 \mathrm{~cm}^{-1}$ corresponding to the carbonyl stretching of PLLA increases. Finally, for the polymers with 15 higher content of PLLA, (line on the top) the peak at $1756 \mathrm{~cm}^{-1}$ appears more intense.
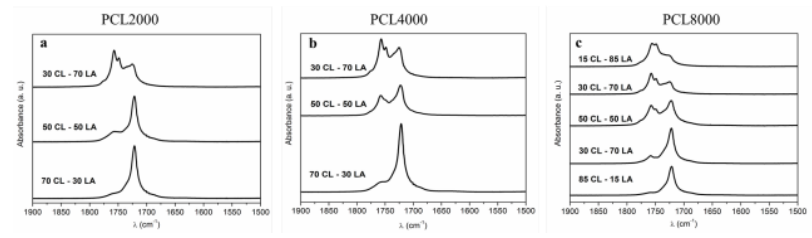

Fig. 2. Carbonyl stretching FT-IR spectra of tri-block 20 copolymers: a) synthesized from PCL2000, b) synthesized from PCL4000 and c) synthesized from PCL8000.

\section{Synthesis of poly(ester-urethane)s}

Starting from the synthesized tri-block copolymers with hydroxyl groups at the end of the chain, a polycondensation reaction using

${ }_{25} \mathrm{HDI}$ at 1:1 molar concentration was carried out. In this manner the PLLA blocks were linked through urethane bonds. The formation of the urethane bonds was confirmed by FT-IR analysis.

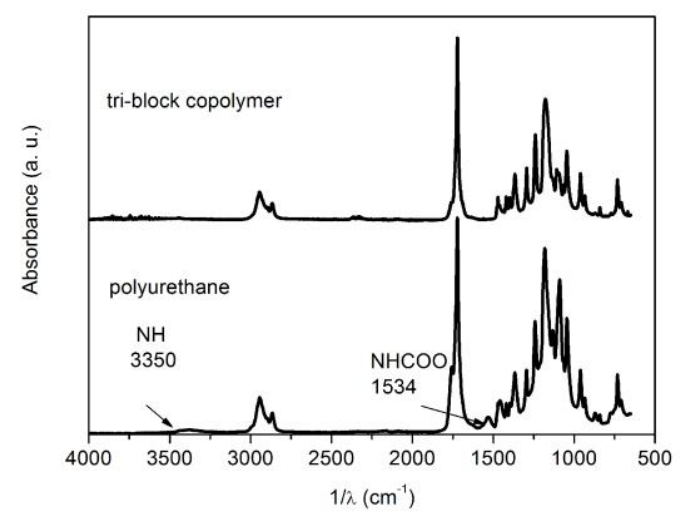

Fig. 3. FT-IR spectrum for T6 and PU6.

30

In Fig. 3, two examples of FT-IR spectra corresponding to a triblock copolymer (T6) and its corresponding poly(ester-urethane), are shown. The characteristic peaks for PCL and PLLA can be seen, and for the poly(ester-urethane), new peaks at about 1534 $35 \mathrm{~cm}^{-1}$ due to the amide II band of the urethane bond and around $3500 \mathrm{~cm}^{-1}$ due to the $\mathrm{NH}$ stretching of the urethane group, appear. $^{23}$ The presence of these new peaks confirms the reaction

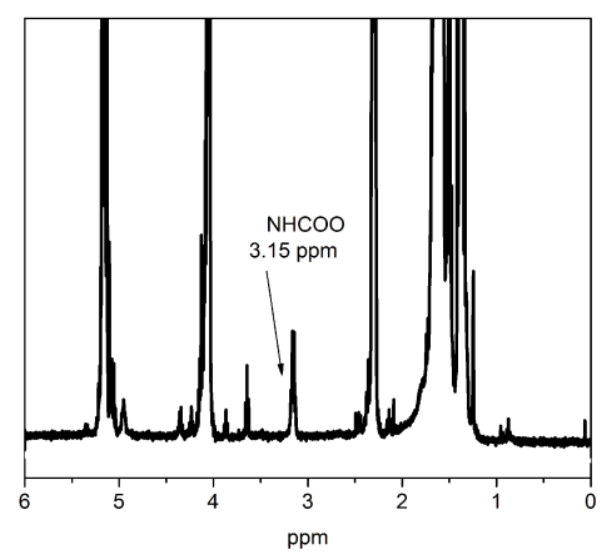

between the hydroxyl end groups of tri-block copolymers and the isocyanate groups of HDI. ${ }^{19}$ Another way to confirm urethane 40 formation is by ${ }^{1} \mathrm{H}$ NMR. So, in Fig. 4 the ${ }^{1} \mathrm{H}$ NMR spectrum for PU6 is reported. Thus, the presence of a new peak at $3.15 \mathrm{ppm}$ confirms the formation of urethane groups. ${ }^{17-24}$ Moreover the signal corresponding to the PLLA end groups (peak at $4.35 \mathrm{ppm}$ ) disappears almost completely, confirming that the condensation 45 reaction between the isocyanate groups of HDI and the hydroxyl groups of the tri-block copolymer proceeded correctly.

Fig. 4. ${ }^{1} \mathrm{H}$ NMR spectrum of PU6.

\section{Crystallisation analysis}

The thermal behaviour of the tri-block copolymers as well as ${ }_{50}$ their crystalline nature have been studied by DSC. The degree of crystallinity $\left(\mathrm{X}_{\mathrm{c}}\right)$ has been estimated considering the value of the melting enthalpy of $100 \%$ crystalline PLLA around $93 \mathrm{KJ} / \mathrm{mol}^{25}$ while for the PCL a value of $148 \mathrm{KJ} / \mathrm{mol}^{26}$ is considered. The DSC thermograms for the synthesized tri-block copolymers are 55 reported in Fig. 5. 


\section{PCL2000}

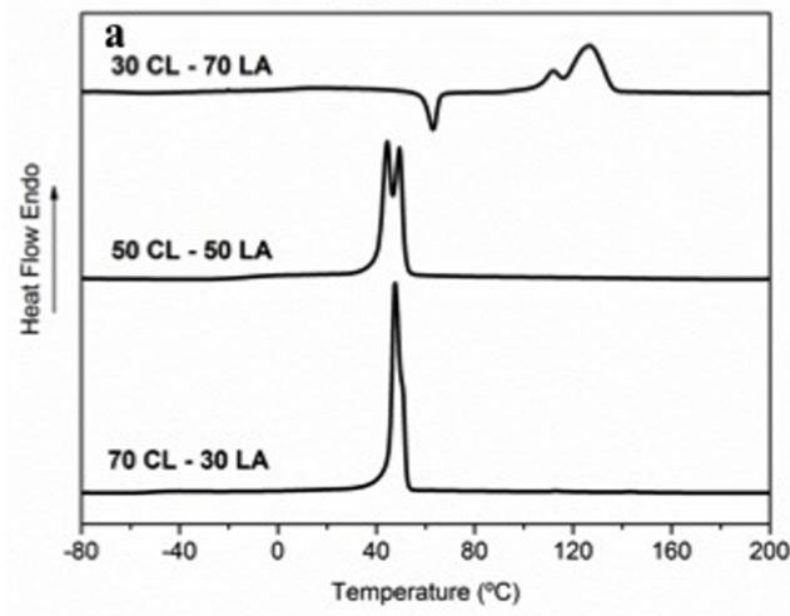

PCL4000

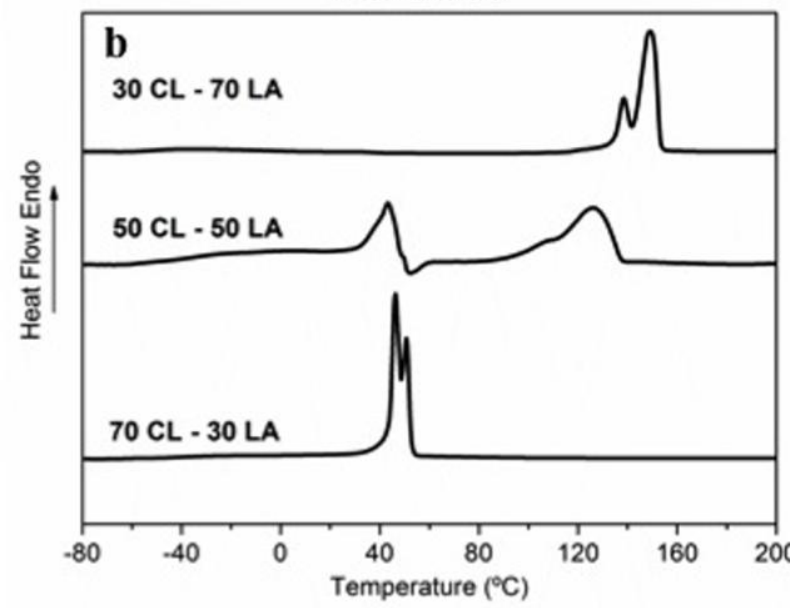

PCL8000

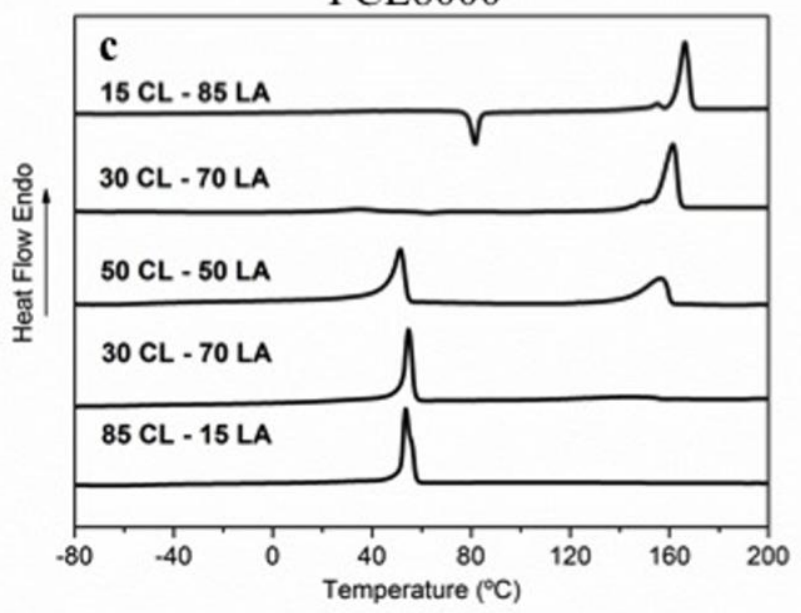

Fig. 5. DSC thermograms of tri-block copolymers (Fig. 5a: triblocks synthesized from PCL2000; Fig. 5b: tri-blocks synthesized from PCL4000; Fig. 5c: tri-blocks synthesized from PCL8000).

10

In order to better understand the effects of the molecular weight on the thermal properties of these materials, the results for the triblocks synthesized from the PCL2000 are reported in Fig. 5a; while those starting from PCL4000 are reported in Fig. 5b and 15 those from PCL8000 are reported in Fig. 5c. Moreover, the theoretical composition of each material is indicated above each thermogram represented in these figures.

Table 2. Thermal properties of the synthesized tri-block 20 copolymers.

\begin{tabular}{|c|c|c|c|c|c|c|c|c|}
\hline $\begin{array}{l}\mathrm{Sa} \\
\mathrm{mp} \\
\mathrm{le}\end{array}$ & $\begin{array}{l}\text { PCL } \\
: P L L \\
\mathrm{~A}\end{array}$ & $\begin{array}{l}\mathrm{M} \\
\mathrm{n}, \mathrm{P} \\
\mathrm{CL} \\
(\mathrm{g} / \\
\mathrm{mo} \\
\text { 1) }\end{array}$ & $\begin{array}{l}\text { Mn, } \\
\text { PLLA } \\
\text { tot } \\
\text { (g/ } \\
\text { mol } \\
\text { ) }\end{array}$ & $\begin{array}{l}\mathrm{T}_{\mathrm{m}} \\
, \mathrm{PC} \\
\mathrm{L} \\
\left({ }^{\mathrm{o}}\right. \\
\mathrm{C})\end{array}$ & $\begin{array}{l}X_{c} \\
, P C \\
L \\
( \\
\% \\
)\end{array}$ & $\begin{array}{l}\mathrm{T}_{\mathrm{m}} \\
\mathrm{PLL} \\
\mathrm{A} \\
\left({ }^{\circ} \mathrm{C}\right. \\
)\end{array}$ & $\begin{array}{l}X_{c}, \\
\text { PLL } \\
\text { A } \\
(\% \\
)\end{array}$ & $\begin{array}{l}\mathrm{T}_{\mathrm{g}} \\
\text {,PC } \\
\mathrm{L} \\
\left({ }^{\circ}\right. \\
\mathrm{C})\end{array}$ \\
\hline $\mathrm{T} 1$ & $\begin{array}{l}92: 0 \\
8 \\
\end{array}$ & $\begin{array}{l}80 \\
49 \\
\end{array}$ & 686 & 54 & 44 & - & 0 & $\begin{array}{l}- \\
54\end{array}$ \\
\hline $\mathrm{T} 2$ & $\begin{array}{l}89: 1 \\
1\end{array}$ & $\begin{array}{l}20 \\
54\end{array}$ & 252 & 48 & 50 & - & 0 & $\begin{array}{l}- \\
53\end{array}$ \\
\hline T3 & $\begin{array}{l}84: 1 \\
6 \\
\end{array}$ & $\begin{array}{l}40 \\
21 \\
\end{array}$ & 787 & 46 & 50 & - & 0 & $\begin{array}{l}- \\
40\end{array}$ \\
\hline $\mathrm{T} 4$ & $\begin{array}{l}77: 2 \\
3 \\
\end{array}$ & $\begin{array}{l}80 \\
49 \\
\end{array}$ & $\begin{array}{l}234 \\
4 \\
\end{array}$ & 55 & 44 & $\begin{array}{l}14 \\
2 \\
\end{array}$ & 49 & $\begin{array}{l}- \\
56 \\
\end{array}$ \\
\hline T5 & $\begin{array}{l}73: 2 \\
7 \\
\end{array}$ & $\begin{array}{l}20 \\
54 \\
\end{array}$ & 774 & 44 & 43 & - & 0 & $\begin{array}{l}- \\
13 \\
\end{array}$ \\
\hline T6 & $\begin{array}{l}54: 4 \\
6 \\
\end{array}$ & $\begin{array}{l}40 \\
21 \\
\end{array}$ & $\begin{array}{l}335 \\
4\end{array}$ & 43 & 9 & $\begin{array}{l}12 \\
6\end{array}$ & 47 & - \\
\hline $\mathrm{T} 7$ & $\begin{array}{l}54: 4 \\
6\end{array}$ & $\begin{array}{l}80 \\
49\end{array}$ & $\begin{array}{l}697 \\
3\end{array}$ & 51 & 32 & $\begin{array}{l}15 \\
6\end{array}$ & 44 & $\begin{array}{l}- \\
59\end{array}$ \\
\hline $\mathrm{T} 8$ & $\begin{array}{l}34: 6 \\
6 \\
\end{array}$ & $\begin{array}{l}20 \\
54 \\
\end{array}$ & $\begin{array}{l}400 \\
2\end{array}$ & - & 0 & $\begin{array}{l}12 \\
9\end{array}$ & 50 & - \\
\hline T9 & $\begin{array}{l}33: 6 \\
7 \\
\end{array}$ & $\begin{array}{l}80 \\
49 \\
\end{array}$ & $\begin{array}{l}165 \\
59\end{array}$ & 34 & 7 & $\begin{array}{l}16 \\
2\end{array}$ & 59 & $\begin{array}{l}- \\
49\end{array}$ \\
\hline $\begin{array}{l}\text { T1 } \\
0\end{array}$ & $\begin{array}{l}32: 6 \\
8\end{array}$ & $\begin{array}{l}40 \\
21\end{array}$ & $\begin{array}{l}848 \\
1\end{array}$ & - & 0 & $\begin{array}{l}14 \\
9\end{array}$ & 54 & $\begin{array}{l}- \\
49\end{array}$ \\
\hline $\begin{array}{l}\text { T1 } \\
1 \\
\end{array}$ & $\begin{array}{l}18: 8 \\
2\end{array}$ & $\begin{array}{l}80 \\
49 \\
\end{array}$ & $\begin{array}{l}373 \\
26\end{array}$ & - & 0 & $\begin{array}{l}16 \\
6\end{array}$ & 57 & - \\
\hline
\end{tabular}

The values of $\mathrm{T}_{\mathrm{m}}, \mathrm{T}_{\mathrm{g}}$ and $\mathrm{X}_{\mathrm{c}}$ obtained from the DSC experiments 25 are summarized in Table 2 for each material. It is evident that the melting temperatures as well as the enthalpies of melting are strongly influenced by the composition of the copolymer. The endothermic peaks at temperatures close to $40{ }^{\circ} \mathrm{C}$ correspond to the melting of PCL blocks while those at higher temperature 
correspond to the melting of PLLA. On the other hand, the exothermal peaks that appear in some of the DSC scans between $60{ }^{\circ} \mathrm{C}$ and $80^{\circ} \mathrm{C}$ correspond to the cold crystallisation of PLLA. In the samples with high content of PLLA, such as 70 and $85 \mathrm{wt}$ ${ }_{5} \%$, two endothermic peaks, indicating a double melting point of the PLLA-block are presented. The appearance of this phenomenon has also been reported in the literature for isothermal and dynamical crystallisation of copolymers of PCLPLLA. Castillo et al. ${ }^{13}$ attributed this phenomenon, observed in 10 di-block copolymers of PCL-PLLA, to a reorganization process during the scan, due to the presence of PCL. Sarasua et al. attributed the double peak of different synthesized PLLA homopolymers to the annealing occurring during the DSC scans where the small crystals had time to recrystallize a few degrees 15 above and to remelt. ${ }^{27}$ It has also been reported that the presence of different peaks in the melting of PLLA could be induced by changes in the crystallisation behaviour induced during processing. For instance, Sonseca et al. ${ }^{28}$ observed a similar crystallisation behaviour induced by the alignment of the 20 electrospun fibres in PLLA fibre mats.

The influence of the molecular weight of each block on the $T_{m}$ and on the degree of crystallinity for the tri-blocks is reported in Fig. 6. It is clear that the crystallisation of the PCL-block is affected by the presence of crystalline PLLA-block (white 25 circles) and of the amorphous PLLA (black squares). In particular, Fig. 6a represents the $\mathrm{T}_{\mathrm{m}}$ of PCL and Fig. $6 \mathrm{~b}$ the degree of crystallinity of PCL. In tri-blocks with amorphous PLLA-block (Fig. 6a) the melting temperature of the PCL-block slightly increases with the increase in the molecular weight of the ${ }_{30}$ PCL block. And, when PLLA blocks crystallizes, the restrictions imposed by the presence of the PLLA crystals reduces the ability of the PCL blocks to crystallize, and the resulting crystals are smaller and less perfect, resulting in a lower melting point of the PCL crystals. These restrictions increased with the length and the 35 content of the PLLA block, as it can be seen in Table 2 (entries T4, T7 and T9) for the tri-blocks based on PCL 8000, until the PCL crystallinity is completely suppressed (entry T11). Fig. 6b shows the degree of crystallinity of the PCL-block. The copolymers with amorphous PLLA (black squares) show a degree 40 of crystallinity around $50 \%$, as already found for PCL-PLLA diblocks with amorphous PLLA. ${ }^{14}$ On the other hand, when PLLAblock is crystalline (white circles), the degree of crystallinity of the PCL-block is strongly reduced for all the compositions analysed and in particular, the degree of crystallinity of the PCL-

45 block, at the same molecular weight, decreased with increasing the length of the PLLA blocks, until complete suppression. At similar PLLA block length, the decrease was higher at lower molecular weight of the PCL block (see entries T7 and T10 in Table 2). A significant difference is found respect to the ${ }_{50}$ crystallisation of PCL in di-block copolymers, as reported before by our research group. ${ }^{14}$ For di-block copolymers, when the PLLA block was crystalline, PCL started to crystallize for PCL molecular weight higher than $2000 \mathrm{~g} / \mathrm{mol}$ and the crystalline content increased exponentially until it reached a plateau at 6500 $55 \mathrm{~g} / \mathrm{mol}$ with a value of approximately $50 \%$ irrespective of the PLLA content. Only at intermediate concentrations (PCL:PLA 50:50 by weight) PCL crystallized substantially without a strong restriction promoted by the presence of PLLA crystals. For the tri-blocks synthesized here, the length and the content of PLLA${ }_{60}$ block strongly influence the PCL crystallinity. Thus, for the PCL 8000 series, when PLLA content is increased, PCL crystallisation is reduced until complete suppression (entries T4, T7, T9 and T10) in parallel to the decrease found in the melting point of the crystals.

65
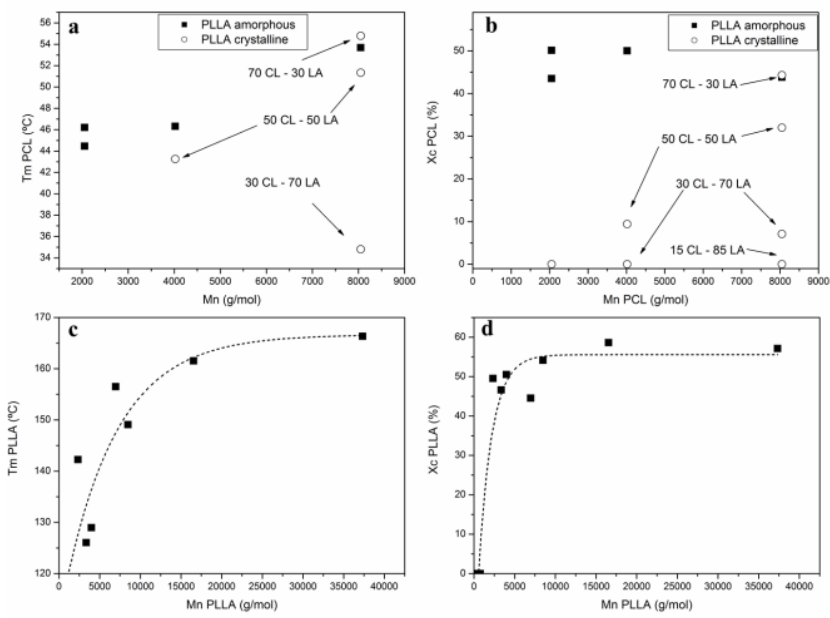

Fig. 6. Melting temperature $\left(\mathrm{T}_{\mathrm{m}}\right)$ and degree of crystallinity $\left(\mathrm{X}_{\mathrm{c}}\right)$ of tri-block copolymers vs. molecular weight of PCL $(6 \mathrm{a}, 6 \mathrm{~b})$ and PLLA (6c, 6d) respectively.

70

PLLA melting temperature and degree of crystallisation are represented in Fig. 6c and 6d respectively. PLLA crystallinity starts at $2340 \mathrm{~g} / \mathrm{mol}$ and reaches a plateau very rapidly. Coherent with the crystallisation behaviour, the PLLA melting point 75 increases with the PLLA block length until it almost level is reached above $17000 \mathrm{~g} / \mathrm{mol}$. This behaviour is similar to the one found for di-block copolymers. ${ }^{14}$ For di-block copolymers, PLLA crystallisation started at a PLLA molecular weight of $964 \mathrm{~g} / \mathrm{mol}$ and the crystallisation was not influenced by the presence of PCL ${ }_{80}$ reaching a plateau at approximately $2500 \mathrm{~g} / \mathrm{mol}$. Moreover, for di-block copolymers, the PLLA melting point was also dependent on the PLLA molecular weight but maximum melting point was reached at about $7500 \mathrm{~g} / \mathrm{mol}$. In the case of the tri-block copolymers synthesized in this work, if it is considered that the 85 total PLLA molecular weight is equally distributed in the two branches linked to the PCL-block, the melting point reaches the maximum value at approximately $8500 \mathrm{~g} / \mathrm{mol}$ whereas crystallisation started at $1170 \mathrm{~g} / \mathrm{mol}$ and a plateau at approximately $3000 \mathrm{~g} / \mathrm{mol}$, which are in good agreements with 90 the values found for di-block copolymers. In addition, the values for $\mathrm{T}_{\mathrm{m}}$ and maximum crystallinity for PLLA in the tri-blocks, approximately $165{ }^{\circ} \mathrm{C}$ and $55 \%$, respectively, are practically the same values achieved in the di-blocks composition. These similarities demonstrate that PLLA blocks in tri-block 95 copolymers have the same ability to crystallize that in di-block copolymers and that the main parameter that influences the PLLA crystallisation is its block length ${ }^{14}$.

The effects of the block composition on the glass transition temperature were also analysed by DSC. As reported in literature, ${ }_{100}$ PCL and PLLA form immiscible or partially miscible systems. ${ }^{10,13,29}$ Typically, the $\mathrm{T}_{\mathrm{g}}$ of pure PCL is around $-60{ }^{\circ} \mathrm{C}$ 
while for pure PLLA is around $60{ }^{\circ} \mathrm{C}$, depending on their molecular weight and tacticity. ${ }^{29}$

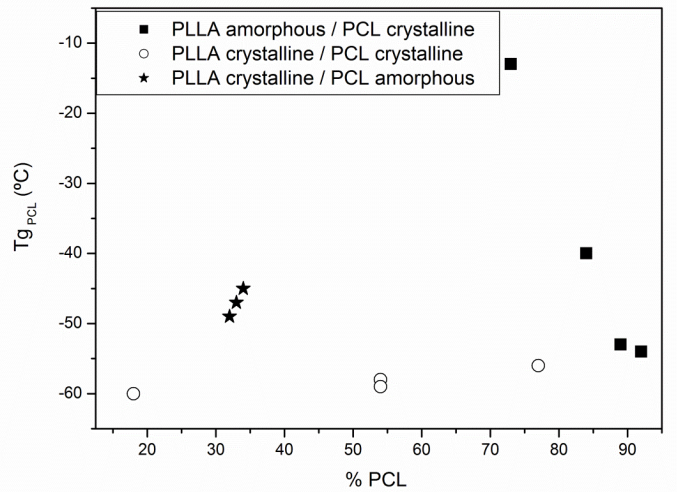

Fig. 7. Glass transition temperatures of tri-block copolymers.

The $\mathrm{T}_{\mathrm{g}}$ of the PCL-blocks are reported in Fig. 7. The values were divided in three different sets: tri-blocks with amorphous PCLblock (black stars), those with crystalline PCL-block and amorphous PLLA-block (black squares) and those with both 10 crystalline blocks (white circles). It is worth to note that triblocks with both crystalline blocks show a $\mathrm{T}_{\mathrm{g}}$ of the PCL-block around $-60{ }^{\circ} \mathrm{C}$, which increases slightly with the PCL-block content. In the case of tri-blocks with amorphous PLLA-blocks and crystalline PCL-block (black squares) a strong influence of 15 the composition of the copolymers has been found. This fact indicates a strong interaction of the amorphous PLLA and PCL chains promoting a partial miscibility between the blocks. This effect appears also in copolymers with crystalline PLLA-blocks and amorphous PCL-blocks (black stars). The depression of $\mathrm{T}_{\mathrm{m}}$

20 (Fig. 6) of each block and the changes on $T_{g}$ (Fig. 7) reveal that there is a partial miscibility of the two blocks in these copolymers. The glass transition of the PLLA-block is difficult to measure from DSC thermograms because it is in the range of the $\mathrm{T}_{\mathrm{m}}$ of the PCL-block. ${ }^{30}$

${ }_{25}$ In Fig. 8 the thermograms corresponding to the second heating scan of the poly(ester-urethane)s synthesized from the tri-block copolymers are reported.

Striking differences on the melting temperatures as well as on the degree of crystallinity compared with the initial tri-block 30 copolymers have been obtained on the poly(ester-urethane)s as shown in Table 3, where the amounts of HDI in the poly(esterurethane)s are reported in order to easily understand the effects of the urethane bonds on the thermal properties. As shown in Fig. 8, the poly(ester-urethane)s are less crystalline than the initial 35 corresponding tri-block copolymers. Furthermore, in this case there is a cold crystallisation process in the second heating scan indicating that the polymer chains could not crystallize during the cooling step at the cooling rate used. The exothermal peaks at about $0{ }^{\circ} \mathrm{C}$ correspond to the cold crystallisation of PCL while 40 those between $60{ }^{\circ} \mathrm{C}$ and $80{ }^{\circ} \mathrm{C}$ correspond to the cold crystallisation of the PLLA. The appearance of these crystallisation peaks is due to the amorphisation during cooling at the cooling rates used as a consequence of the restrictions imposed to the tri-block chains by the urethane linkages.
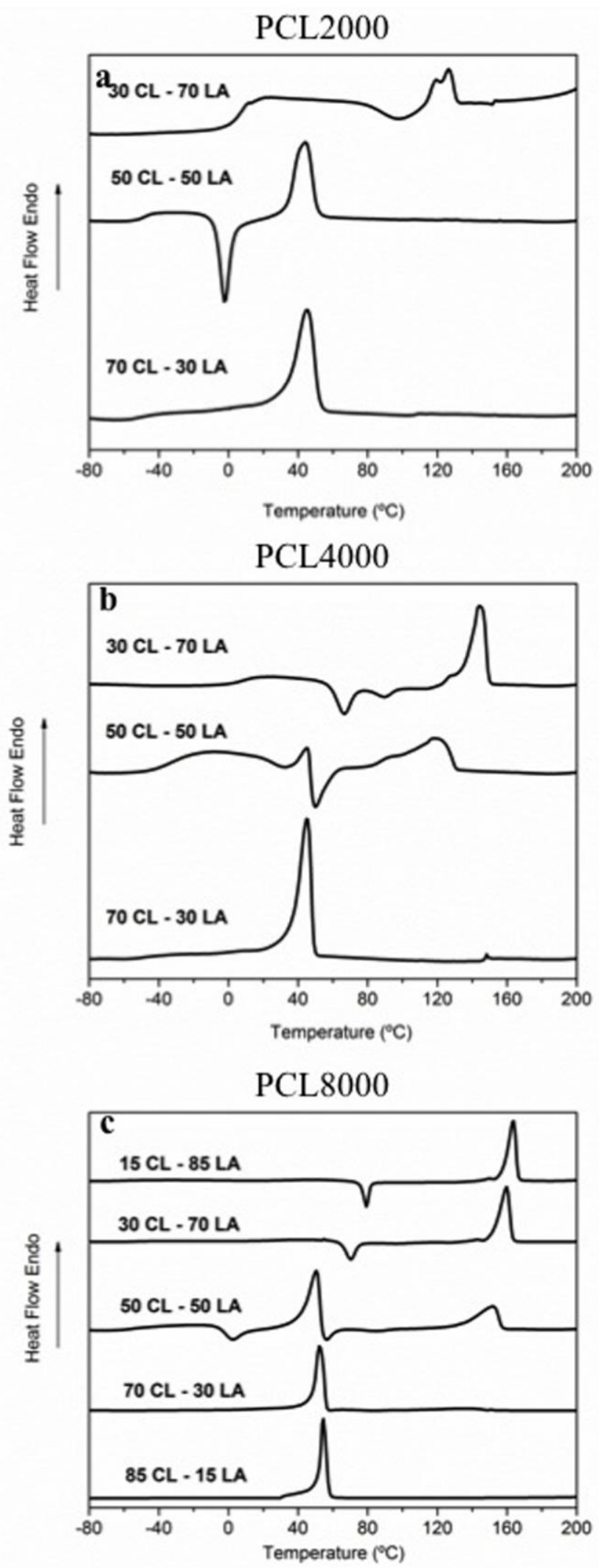

${ }_{45}$ Fig. 8. DSC thermograms of synthesized poly(ester-urethane)s (Fig. 8a: PUs from tri-blocks synthesized from the PCL2000; Fig. 8b: PUs from tri-blocks synthesized from PCL4000; Fig. 8c: PUs from tri-blocks synthesized from PCL8000). 
Table 3. Thermal properties of the synthesized poly(esterurethane)s. intramolecular hydrogen bonds that restrict further the movement of the chains.

Fig. 9 reports the values of the $\mathrm{T}_{\mathrm{m}}$ and the degree of crystallinity for both blocks in the synthesized poly(ester-urethane)s as a

\begin{tabular}{|c|c|c|c|c|c|c|c|c|c|}
\hline $\begin{array}{l}\mathrm{Sa} \\
\mathrm{mpl} \\
\mathrm{e}\end{array}$ & $\begin{array}{l}\text { P } \\
\text { C } \\
\text { L: } \\
\text { P } \\
\text { L } \\
\text { L } \\
\text { A }\end{array}$ & $\begin{array}{l}\text { Mn } \\
\text { PC } \\
\text { L } \\
\text { (g/ } \\
\text { mo } \\
\text { l) }\end{array}$ & $\begin{array}{l}\mathrm{Mn}, \mathrm{P} \\
\text { LLAtot } \\
(\mathrm{g} / \mathrm{m} \\
\mathrm{ol})\end{array}$ & $\begin{array}{l}\text { H } \\
\text { D } \\
\text { I } \\
( \\
\% \\
\text { ( }\end{array}$ & $\begin{array}{l}\mathrm{T}_{\mathrm{m}} \\
\mathrm{PCL} \\
\left({ }^{\circ} \mathrm{C}\right. \\
)\end{array}$ & $\begin{array}{l}\mathrm{X}_{\mathrm{c}} \\
\mathrm{PCL} \\
(\% \\
)^{\%}\end{array}$ & $\begin{array}{l}\mathrm{T}_{\mathrm{m}}, \\
\text { PLL } \\
\text { A } \\
\left({ }^{\circ} \mathrm{C}\right. \\
)\end{array}$ & $\begin{array}{l}X_{c, P} \\
\text { LLA } \\
(\%)\end{array}$ & $\begin{array}{l}\text { Tfunction of the molecular weight of each block. PCL melting } \\
\text { pont is barely reduced in the PUs based on tri-blocks o } \\
\text {,P } \text { PCL8000 and PCL } 4000 \text { (Fig.9a), but it was significantly reduced } \\
\text { L in PUs based on tri-blocks of PCL2000. Changes in PCL } \\
\text { (o crystallinity are more notorious, and, when PUs with the same } \\
\text { CDCL length are compared, PCL crystallinity is increasingly } \\
\text { reduced when the PLLA content in the tri-block is increased (see } \\
\text { for example entries PU1, PU4 and PU7 in Table 3). Thi }\end{array}$ \\
\hline PU & $\begin{array}{l}92 \\
: 0 \\
8\end{array}$ & $\begin{array}{l}80 \\
49\end{array}$ & 686 & $\begin{array}{l}1 . \\
8 \\
9\end{array}$ & 53 & 46 & - & 0 & $\begin{array}{l}\text { reduction is also dependent on the PCL block length, with a } \\
5 \text { drastic reduction for PCL } 2000 \text { (compare T5 in Table } 2 \text { with PUS } \\
\text { Table } 2 \text { with PU7 in Table 3), and intermediate reduction for PCL }\end{array}$ \\
\hline $\begin{array}{l}\text { PU } \\
2\end{array}$ & $\begin{array}{l}89 \\
: 1 \\
1\end{array}$ & $\begin{array}{l}20 \\
54\end{array}$ & 252 & $\begin{array}{l}6 . \\
8 \\
0\end{array}$ & 45 & 29 & - & 0 & $\begin{array}{l}-40 \text { 0 (compare T3 in Table } 2 \text { with PU3 in Table } 3 \text { ). Thus, the } \\
5 \text { multi-block formation by the reaction of the tri-blocks with } \\
\text { diilsocyanate reduced the PCL crystallinity, with increased effects }\end{array}$ \\
\hline $\begin{array}{l}\mathrm{PU} \\
3\end{array}$ & $\begin{array}{l}84 \\
: 1 \\
6\end{array}$ & $\begin{array}{l}40 \\
21\end{array}$ & 787 & $\begin{array}{l}3 . \\
3 \\
8\end{array}$ & 48 & 39 & - & 0 & $4 \sqrt[5]{3 .-4}$ \\
\hline $\begin{array}{l}\text { PU } \\
4\end{array}$ & $\begin{array}{l}77 \\
: 2 \\
3\end{array}$ & $\begin{array}{l}80 \\
49\end{array}$ & 2344 & $\begin{array}{l}1 . \\
5 \\
9\end{array}$ & 52 & 39 & $\begin{array}{l}13 \\
7\end{array}$ & 24 & $\cdot$ \\
\hline $\begin{array}{l}\text { PU } \\
5\end{array}$ & $\begin{array}{l}73 \\
: 2 \\
7\end{array}$ & $\begin{array}{l}20 \\
54\end{array}$ & 774 & $\begin{array}{l}5 . \\
6 \\
1\end{array}$ & 41 & 0.5 & - & 0 & 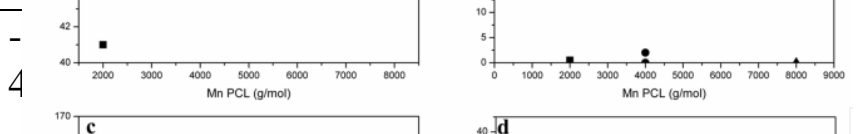 \\
\hline $\begin{array}{l}\text { PU } \\
6\end{array}$ & $\begin{array}{l}54 \\
: 4 \\
6\end{array}$ & $\begin{array}{l}40 \\
21\end{array}$ & 3354 & $\begin{array}{l}2 . \\
2 \\
3\end{array}$ & 45 & 2 & $\begin{array}{l}11 \\
8\end{array}$ & 0 & 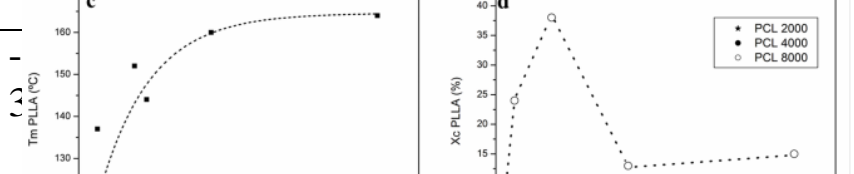 \\
\hline $\begin{array}{l}\text { PU } \\
7\end{array}$ & $\begin{array}{l}54 \\
: 4\end{array}$ & $\begin{array}{l}80 \\
49\end{array}$ & 6973 & $\begin{array}{l}1 . \\
1\end{array}$ & 51 & 25 & $\begin{array}{l}15 \\
2\end{array}$ & 38 & 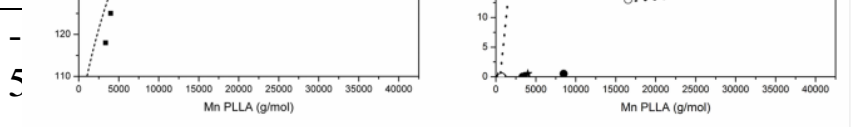 \\
\hline
\end{tabular}

\begin{tabular}{|l|l|l|l|l|l|l|l|l|l|l|}
\hline & 6 & & & 1 & & & & & \\
\hline 8 & 34 & 20 & 4002 & 2. & - & 0 & 12 & 0.5 & - \\
7 & 54 & & & & 5 & & 4 \\
& 6 & & & 0 & & & & & 35 \\
\hline PU & 33 & 80 & 1655 & 0. & - & 0 & 16 & 13 & - \\
9 & $: 6$ & 49 & 9 & 6 & & & 0 & & 6 \\
& 7 & & & 8 & & & & & \\
\hline PU & 32 & 40 & 8481 & 1. & - & 0 & 14 & 0.5 & 70 \\
10 & $: 6$ & 21 & & 3 & & & 4 & & 49 \\
& 8 & & & 3 & & & & & \\
\hline PU & 18 & 80 & 3732 & 0. & - & 0 & 16 & 15 & - \\
11 & $: 8$ & 49 & 6 & 3 & & & 4 & & 5 \\
& 2 & & & 7 & & & & & 5 \\
\hline
\end{tabular}

Whereas in the tri-blocks, the PLLA blocks are at the chain ends and are free to crystallize, in the poly(ester-urethane), with a segmented structure, the PLLA blocks are now part of a longer chain that restricts the movements of the individual blocks. In 10 addition, the urethane groups can form intermolecular and
Fiф. 9. Melt transition temperature $\left(\mathrm{T}_{\mathrm{m}}\right)$ and degree of crystallinity $\left(\mathrm{X}_{\mathrm{c}}\right)$ of poly(ester-urethanes) vs. molecular weight of $45 \mathrm{CL}(9 \mathrm{a}, 9 \mathrm{~b})$ and PLLA (9c, 9d) blocks respectively. 35

Similar tendencies were found for PLLA blocks. The PLLA 6 (f)elting point is slightly reduced (Fig.9c) by poly(ester-urethane) formation but it follows the same tendency than for the tri-block precursors. However, the PLLA crystallinity is strongly affected 70 in the poly(ester-urethane)s (Fig. 9d). PLLA crystallinity in PUs 49ased on PCL 2000 and PCL 4000 is negligible and only PUs based on PCL 8000 crystallize significantly, indicating an important different behaviour with respect to the corresponding trifblock copolymers. Moreover, analysing the PUs behaviour, 54 (Fig. 9, Table 3) a maximum in the PCL crystallinity has been reached at the smaller PLLA molecular weight. This fact can be due to the higher concentration of the urethane bonds at smaller PLLA molecular weight, thus considering the 1:1 molar ratio in the poly(ester-urethane) composition. However the degrees of ${ }_{50}$ crystallinity shown by poly(ester-urethane)s are lower than the values obtained for the corresponding tri-blocks probably due to mobility restrictions imposed by the urethane linkages. When 
PU4 (based on PCL 8000) and PU6 (based on PCL4000) are compared, PU6 has longer PLLA blocks than PU4, and therefore a higher crystallinity was expected while, indeed, PU6 is almost amorphous. However, if the total molecular weight of the tri5 block is evaluated, PU6 is shorter than PU4 (7375 g/mol vs. $10393 \mathrm{~g} / \mathrm{mol}$ ) and therefore, urethane groups concentration in PU6 is higher than in PU4, leading to a higher concentration of hydrogen bonds and a stronger restriction of the chain mobility. These facts can be confirmed by further evaluation of the values 10 of degree of crystallinity as well as of wt $\%$ of HDI reported in the table 3. In fact, PU4 presents $1.59 \mathrm{wt} \%$ HDI and a degree of crystallinity of $24 \%$. PU7, with a $1.11 \mathrm{wt} \%$ HDI shows a degree of crystallinity of $38 \%$ and PU9 with a $0.68 \mathrm{wt} \%$ HDI present a degree of crystallinity of $13 \%$. So, it is possible to conclude that 15 the crystallisation restrictions must be considered as determined by complex combined effects of the presence of the urethane groups and of the corresponding hydrogen bonds.

Finally, the values of the $T_{g}$ of the synthesized poly(esterurethane)s are reported in Fig. 10. They can be grouped in three

20 sets depending on the crystalline/amorphous nature of both blocks. In general the $\mathrm{T}_{\mathrm{g}}$ values are slightly higher for the poly(ester-urethane)s compared with their initial corresponding tri-blocks. This fact confirms the contribution of the urethane and hydrogen bonds to the stiffness of the synthesized materials 25 compared to the initial tri-blocks. Moreover, taken into account the melting temperature of PCL and PLLA blocks for the triblocks and for the corresponding crystalline poly(esterurethane)s, it should be noted that the transition temperatures of the poly(ester-urethane)s are shifted with respect to the tri-blocks.

${ }_{30}$ For example T6 shows a $\mathrm{T}_{\mathrm{mPCL}}$ of $43{ }^{\circ} \mathrm{C}$ and a $\mathrm{T}_{\mathrm{mPLLA}}$ of $126{ }^{\circ} \mathrm{C}$ and a $\mathrm{T}_{\mathrm{g}}$ of $-58{ }^{\circ} \mathrm{C}$. Its corresponding U6 shows a $\mathrm{T}_{\mathrm{mPCL}}$ of $45^{\circ} \mathrm{C}$ and a $\mathrm{T}_{\text {mPLLA }}$ of $118{ }^{\circ} \mathrm{C}$ and a $\mathrm{T}_{\mathrm{g}}$ of $-35^{\circ} \mathrm{C}$. That is, the transition temperatures are closer in the PUs than in the corresponding three block copolymers. Although the difference in the melting 35 temperatures is relatively small for both the PCL and the PLLA blocks, it probably indicates smaller and more imperfect crystals formed during the polycondensation of the PUs. The change in the $\mathrm{T}_{\mathrm{g}}$ of PCL towards higher values can be attributed to the higher miscibility of the blocks in the PU respect to the tri-block 40 copolymer. Same behaviour is found for the couple of materials T4/PU4 and T7/PU7.

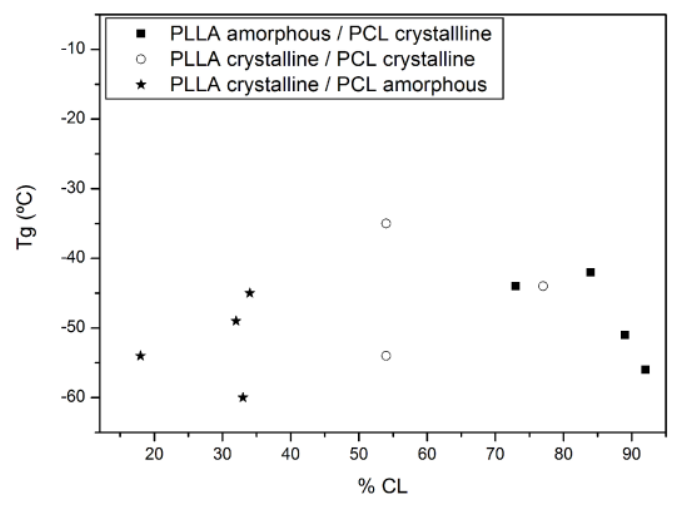

Fig. 10. Glass transition temperature of the synthesized poly(ester-urethane)s.

\section{SAXS Characterization}

${ }_{45}$ The Small Angle X-ray Scattering (SAXS) experiments confirm the existence of a phase-separated morphology in the tri-block copolymers and in the corresponding poly(ester-urethane)s and allow for the determination of the $\mathrm{T}_{\mathrm{m}}$ of both PCL and PLLA blocks. From SAXS experiments, two parameters, the long period 50 (L) that defines the mean distance between the phases and the relative Invariant (Q') that is related to the extent of phase separation, are obtained. $\mathrm{L}$ is calculated using the equation $2 \pi / \mathrm{q}$, where $\mathrm{q}$ is the scattering vector corresponding to a maximum in intensity, and Q' is calculated as the value of the integral below 55 the curve $\mathrm{Iq}^{2}$ vs. $\mathrm{q}$.
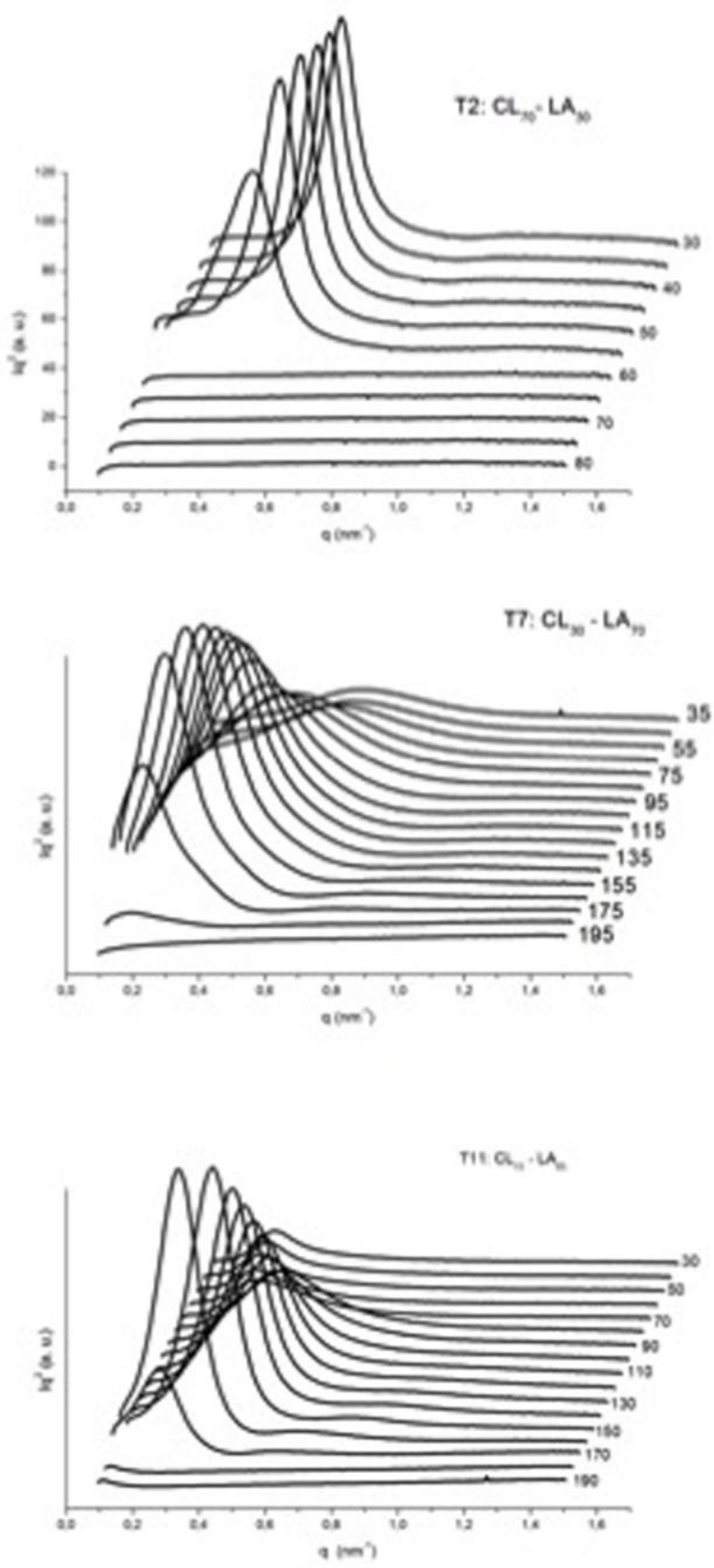

Fig. 11. SAXS experiments for the tri-block copolymers. 
The SAXS spectra are represented in terms of $\mathrm{Iq}^{2}$ vs. q, because this representation is more efficient to detect changes than the representation of I vs. $q$ thus considering that the calculated value for $\mathrm{L}$ from the $\mathrm{Iq}^{2}$ vs. $\mathrm{q}$ representation is correct when the 5 morphology of the phase-separated system is lamellar, as it is the case for PCL and PLLA. ${ }^{31-32}$ In Fig. 11 the scattering curves at different temperatures of three selected samples are represented: T2 with only the PCL-block crystalline, T7 with both blocks able to crystallize and T11 with only the PLLA-block crystalline. The 10 first one shows a peak at room temperature that disappears when the temperature is increased and PCL blocks melt. After PCL melting, no scattering is obtained, indicating that the copolymer forms a homogeneous melt. For T7, the maximum of the scattering peak changes in shape at $60{ }^{\circ} \mathrm{C}$, corresponding to the ${ }_{15} \mathrm{~T}_{\mathrm{m}}$ of PCL, in fact, the peak becomes sharper with increasing temperature indicating that there is a lower dispersity on the size of the remaining PLLA crystals. At higher temperature, when the melting of PLLA is reached, the scattering peak disappears completely leaving a homogeneous melt. For the T11, a change in $20 \mathrm{q}$ and in Q' is found when the temperature reached $60{ }^{\circ} \mathrm{C}$. This phenomenon cannot be due to PCL melting but is related to a cold crystallisation process of PLLA which, in agreement with the DSC curves, taking place at this temperature, Fig. 9. Also in this case, at higher temperature, when the melting of PLLA is 25 reached, the scattering peak disappears completely leaving a homogeneous melt. All the tri-blocks synthesized with only PCL crystalline behave as the copolymer T2; those with both blocks crystalline behave as the copolymer $\mathrm{T} 7$ and those with only PLLA crystalline behave as the copolymer T11. The behaviour 30 for these tri-block copolymers was similar to that found for diblock copolymers. ${ }^{14}$
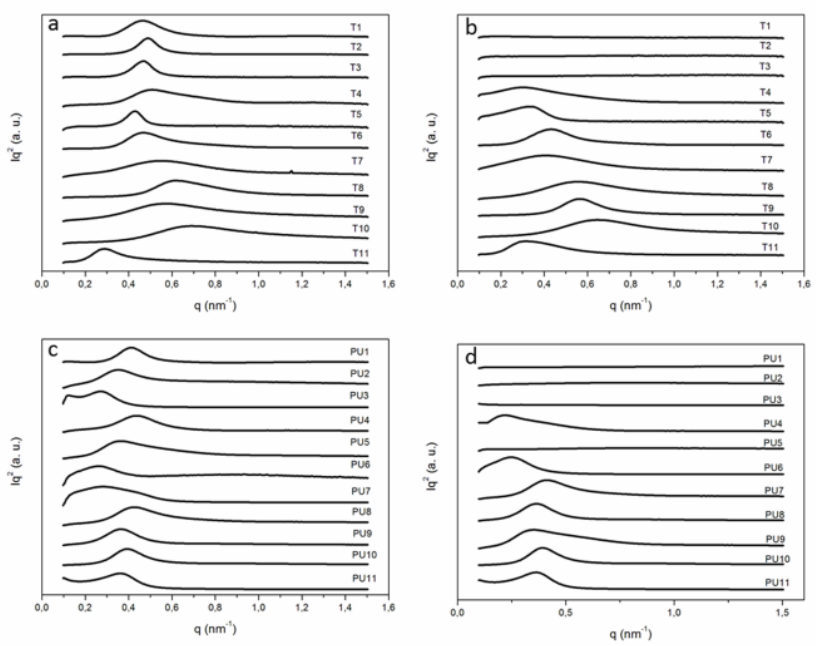

Fig. 12. SAXS curves of tri-block copolymers at: a) $30{ }^{\circ} \mathrm{C}$ and b) $70{ }^{\circ} \mathrm{C}$ and poly(ester-urethane)s: c) $30{ }^{\circ} \mathrm{C}$ and d) $70{ }^{\circ} \mathrm{C}$.

35

Similar SAXS experiments were performed for the synthesized poly(ester-urethane)s. The same changes in q and Q' were found when melting of PCL and PLLA was reached. Moreover, also in this case, when PLLA blocks melted, no scattering was detected, 40 showing that also the poly(ester-urethane)s form a homogeneous melt. Furthermore, for all the materials studied here n) no peaks for nanostructuration of the blocks have been detected from SAXS analysis, as well as from TEM images (data not shown). In Fig. 12 are represented the spectra of all the synthesized tri-block 45 copolymers and their poly(ester-urethane)s at two different temperatures, $30{ }^{\circ} \mathrm{C}$ and $70{ }^{\circ} \mathrm{C}$. In the case of tri-block copolymers at $30{ }^{\circ} \mathrm{C}$, Fig. 12a, all of them are crystalline and show a broad peak. The position of the peak is around $0,5 \mathrm{~nm}^{-1}$ for all copolymers except for the copolymers with high content of ${ }_{50}$ PLLA, where the position is around $0,6 \mathrm{~nm}^{-1}$. T11 shows the peak at lower position, indicating that the polymer cannot crystallize during the sample preparation. However at $70{ }^{\circ} \mathrm{C}$, Fig. $12 \mathrm{~b}$, the peak of T11 moves to higher values, as shown in Fig. 11, due to the cold crystallisation effect. On the other hand the polymers 55 with a PLLA amorphous block do not show the peak at $70{ }^{\circ} \mathrm{C}$ indicating that the system is completely molten and homogenous at this temperature. Finally, for the tri-block copolymers with both crystalline blocks at this temperature the peak shifts to lower values of $q$ in all cases.

${ }_{60}$ Differences between tri-block copolymers and poly(esterurethane)s are revealed by SAXS experiments, as reported in Fig. $12 \mathrm{c}$ and Fig. $12 \mathrm{~d}$. It is worth to note that the spectrum at $70{ }^{\circ} \mathrm{C}$ of the sample PU5 with amorphous PLLA blocks, has no peaks, while the initial tri-block, T5, is crystalline.

65

Table 4. Long period $\mathrm{L}$ at $30{ }^{\circ} \mathrm{C}$ and $70{ }^{\circ} \mathrm{C}$ for the tri-blocks and their corresponding poly(ester-urethane)s.

\begin{tabular}{|l|l|l|l|l|l|}
\hline Sample & PCL:PLLA & $\begin{array}{l}\text { Long period (tri- } \\
\text { block) }\end{array}$ & \multicolumn{2}{l|}{$\begin{array}{l}\text { Long period } \\
\text { (polyurethane) }\end{array}$} \\
\cline { 3 - 6 } & & $\begin{array}{l}\mathrm{T}= \\
30 \\
\end{array}$ & & $\mathrm{~T}=70^{\circ} \mathrm{C}$ & \multicolumn{2}{|l|}{$\begin{array}{l}\mathrm{T}= \\
{ }^{\circ} \mathrm{C}\end{array}$} & $\mathrm{T}=70^{\circ} \mathrm{C}$ \\
& & 13.6 & - & $\begin{array}{l}30 \\
{ }^{\circ} \mathrm{C}\end{array}$ & \\
\hline 1 & $92: 08$ & 12.9 & - & 15.5 & - \\
\hline 2 & $89: 11$ & 13.4 & - & 18.0 & - \\
\hline 3 & $84: 16$ & 12.3 & 21.5 & 21.0 & - \\
\hline 4 & $77: 23$ & 14.6 & - & 14.5 & 28.8 \\
\hline 5 & $73: 27$ & 13.4 & 14.7 & 24.2 & - \\
\hline 6 & $54: 46$ & 18.3 & 15.5 & 17.5 & 17.8 \\
\hline 7 & $54: 46$ & 10.1 & 11.5 & 15.5 & 21.5 \\
\hline 8 & $34: 66$ & 11.1 & 16.3 & 17.5 & 17.5 \\
\hline 9 & $33: 67$ & 9.1 & 14.1 & 16.0 & 16.0 \\
\hline 10 & $32: 68$ & 21.7 & 14.9 & 17.3 & 17.3 \\
\hline 11 & $18: 82$ & & & & \\
\hline
\end{tabular}

${ }_{70}$ In order to better visualize these differences the values of the long period for the tri-blocks as well as for the poly(ester-urethane)s are summarized in Table 4, at two different temperatures, such as $30{ }^{\circ} \mathrm{C}$ and $70{ }^{\circ} \mathrm{C}$, that is, below and above the melting temperature of PCL. Table 4 shows that the long period L in the 75 tri-blocks having both crystalline blocks, increases when PCL is in the molten state. Only for T11, the long period value decreases with increasing temperature, thus indicating the cold crystallisation phenomenon as observed in the second cycle of DSC. However, comparing T11 with PU11, it is worth to note 80 that in PU11 this behaviour is not observed, and the long period is the same at $30{ }^{\circ} \mathrm{C}$ and at $70{ }^{\circ} \mathrm{C}$. This difference can be attributed to the different sample processing conditions, because the tri-blocks have been molten and cooled at room temperature 
in an aluminum pan, while the poly(ester-urethane)s have been closed in aluminum foil without further thermal treatments before SAXS spectra were recorded. For the tri-blocks, L ranges from 9.1 to $21.7 \mathrm{~nm}$ at $30{ }^{\circ} \mathrm{C}$ and from 11.5 to $21.5 \mathrm{~nm}$ at $70{ }^{\circ} \mathrm{C}$. The 5 same range of values has been found for di-block copolymers. ${ }^{14}$ For the poly(ester-urethane)s, L ranges from 14.5 to $24.2 \mathrm{~nm}$ at $30{ }^{\circ} \mathrm{C}$ and from 15.2 to $28.8 \mathrm{~nm}$ at $70{ }^{\circ} \mathrm{C}$, and thus comparing every tri-blocks with the corresponding PUs, these ones present higher values. No trend in L values with PCL length or PLLA 10 length was found neither for the tri-blocks nor for the poly(esterurethane)s.
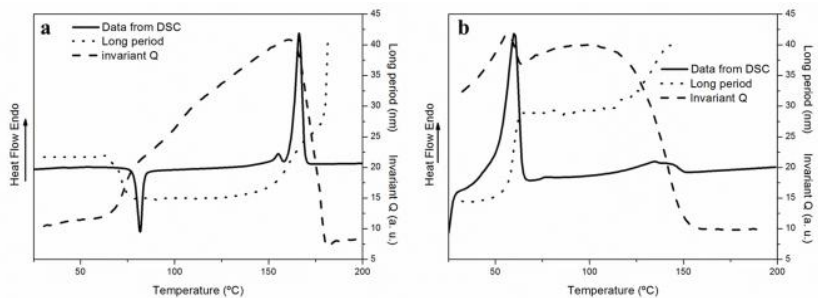

Fig. 13. Comparison of DSC data and SAXS data for: a) tri-block T11 and b) poly(ester-urethane) PU4.

15 The variation of the long period L and invariant Q' with temperature and the thermograms obtained by differential scanning calorimetry for two representative materials are compared in Fig. 13a and Fig. 13b. In particular, Fig. 13a corresponds to the sample T11. In this case it is possible to 20 confirm the cold crystallisation process of this sample by three ways: the exothermic peak from DSC, the change in the invariant and the change in the long period, which reveals the formation of new crystals reducing the separation between them. The melting behaviour of PLLA is similar comparing the results obtained by

25 using both techniques: the endothermic peak of DSC appears at the same range of temperature at which the long period growth to infinity and the invariant Q' starts to reduce until the scattering disappearance indicating that at the end, the blocks are mixed in a homogeneous melt. Fig. 13b shows the poly(ester-urethane) PU4 30 with both crystalline PCL and PLLA blocks. In this sample when the PCL melts, the long period reaches higher values due to the increase of the distance between crystals. After the melting of PCL, $q$ values show a reduction until the PLLA begins to melt, and then the long period starts to increase and the relative 35 invariant Q' starts to decrease until the scattering peak disappears, indicating that a homogeneous melt is formed. Finally, it can be observed that for both materials there is a good agreement between the crystallisation data obtained by the two different characterization techniques applied (DSC and SAXS).

\section{Mechanical properties}

Tensile tests of all synthesized poly(ester-urethane)s were performed except for the sample PU11 due to its high fragility. The stress-strain curves obtained for all the samples analysed are reported in Figure 14, divided in three graphs as a function of the 45 nominal molecular weight of the PCL block. In these figures the curves with the straight lines correspond to the polymers with PLLA-blocks completely amorphous. The values of the elastic modulus, elongation at break and maximum stress are summarized in Table 5. Regarding Figure 14 results, the
${ }_{50}$ polymers show a typical semi-crystalline thermoplastic behaviour characterized by yielding and ductility. In general, the PCL block influences the ductile behaviour while the crystalline PLLA block influences the brittle behaviour. In particular, the copolymers characterized by the presence of amorphous PLLA-blocks (PU2, ${ }_{55}$ PU3 and PU5) and those having the values of PLLA-block crystallinity range from $0 \%$ to $1 \%$ in Table 3 (PU6, PU8 and PU10), show the highest elongation at break. Increasing the PLLA content, the poly(ester-urethane)s become more stiff and brittle, due to the presence of PLLA crystals, showing lower 60 values of the elongation at break(PU4, PU6, PU7 and PU9). On the other hand the poly(ester-urethane)s reported in figure $14 \mathrm{c}$, which have been synthesized using the PCL diol of $8000 \mathrm{~g} / \mathrm{mol}$, have the highest elastic moduli values but the elongation at break is reduced and these polymers are more brittle than the others. ${ }_{65}$ Indeed, we expected that the behaviour of poly(ester-urethane)s rich in PCL and with the (PU1 and PU4) were similar to PU2, PU3 or PU5. So, the results obtained on the mechanical properties indicate that these poly(ester-urethanes)s did not reach a large molecular weight in the polycondensation reaction. The 70 main reason for these low molecular weight obtained can be attributed to the difficulty to define the precise stoichiometric ratio for the polycondensation reaction, as a consequence of the high error in the calculation of the molecular weight of the initial tri-block copolymer by ${ }^{1} \mathrm{H}$ NMR which is not accurate for the 75 computation of high molecular weights.
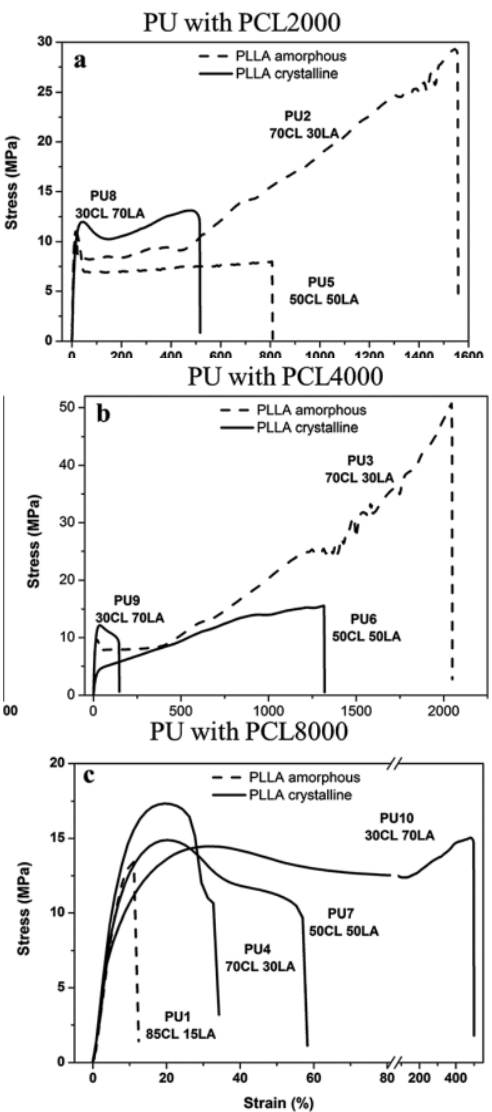

Figure 14. Mechanical properties of poly(ester-urethane)s. 
Table 5. Mechanical properties of poly(ester-urethane)s.

\begin{tabular}{|c|c|c|c|c|}
\hline $\begin{array}{l}\text { Samp } \\
\text { le }\end{array}$ & $\begin{array}{l}\text { PCL:PL } \\
\text { LA }\end{array}$ & $\begin{array}{l}\text { Elastic } \\
\text { modul } \\
\text { us } \\
(\mathrm{MPa})\end{array}$ & $\begin{array}{l}\text { Maxim } \\
\text { un } \\
\text { stress } \\
(\mathrm{MPa})\end{array}$ & $\begin{array}{l}\text { Elongati } \\
\text { on at } \\
\text { break } \\
(\%)\end{array}$ \\
\hline PU1 & 92:08 & $\begin{array}{l}210 \pm \\
30\end{array}$ & $14 \pm 1$ & $\begin{array}{l}10.0 \pm \\
1.5\end{array}$ \\
\hline PU2 & $89: 11$ & $\begin{array}{l}116 \pm \\
12\end{array}$ & $29 \pm 5$ & $\begin{array}{l}1631 \pm \\
127\end{array}$ \\
\hline PU3 & $84: 16$ & $93 \pm 4$ & $49 \pm 4$ & $\begin{array}{l}2020 \pm \\
80\end{array}$ \\
\hline PU4 & $77: 23$ & $\begin{array}{l}230 \pm \\
10\end{array}$ & $\begin{array}{l}17.5 \pm \\
0.1\end{array}$ & $25 \pm 4$ \\
\hline PU5 & $73: 27$ & $\begin{array}{l}123 \pm \\
5\end{array}$ & $\begin{array}{l}8.7 \pm \\
1.8\end{array}$ & $\begin{array}{l}800 \pm \\
200\end{array}$ \\
\hline PU6 & $54: 46$ & $29 \pm 2$ & $\begin{array}{l}16.3 \pm \\
0.6\end{array}$ & $\begin{array}{l}1360 \pm \\
32\end{array}$ \\
\hline PU7 & $54: 46$ & $\begin{array}{l}203 \pm \\
9\end{array}$ & $\begin{array}{l}14.6 \pm \\
0.2\end{array}$ & $30 \pm 5$ \\
\hline PU8 & $34: 66$ & $\begin{array}{l}105 \pm \\
2\end{array}$ & $\begin{array}{l}12.8 \pm \\
0.4\end{array}$ & $537 \pm 25$ \\
\hline PU9 & $33: 67$ & $\begin{array}{l}183 \pm \\
7\end{array}$ & $\begin{array}{l}14.6 \pm \\
0.6\end{array}$ & $\begin{array}{l}400 \pm \\
200\end{array}$ \\
\hline PU10 & $32: 68$ & $\begin{array}{l}110 \pm \\
20\end{array}$ & $\begin{array}{l}11.0 \pm \\
1.5\end{array}$ & $70 \pm 30$ \\
\hline PU11 & $18: 82$ & - & - & - \\
\hline
\end{tabular}

\section{Conclusions}

Eleven linear tri-block copolymers, PLLA-b-PCL-b-PLLA, have 5 been synthesized via ring opening polymerization of L-lactide with three different PCL diols, varying the molecular weight of the blocks as well as the relative content of each block. ${ }^{1} \mathrm{H}$ NMR proved that the desired tri-block structure was obtained and allowed for the determination of the molecular weight and the 10 composition of the tri-blocks. From these tri-blocks, poly(esterurethane)s were synthesized using HDI. The crystallisation behaviour of the tri-block copolymers and the poly(esterurethane)s was studied by DSC and SAXS experiments.

In the tri-block copolymers the crystallinity of the PCL is 15 strongly influenced by the presence and the nature of PLLA. In particular the presence of PLLA crystals is related to a reduction of the crystal size as well as the degree of crystallinity of the PCL blocks. The effect of the presence of PLLA crystals on the PCL crystallinity is stronger in tri-blocks than for PCL-PLLA di20 blocks. The crystallinity of PLLA on the tri-blocks is not influenced by the presence of PCL depending only on the molecular weight of the PLLA block, with no significant difference with PCL-PLLA di-blocks.

Poly(ester-urethane)s showed less degree of crystallinity of both

25 blocks than the initial tri-block precursors due to the restrictions imposed by the multi-block segmented structure of the final poly(ester-urethane). The crystallisation restrictions must be considered as determined by complex combined effects based on the presence of the urethane groups and on the corresponding 30 hydrogen bonds. Moreover, the shift in the $T_{m}$ values of both crystalline blocks towards closer values in the poly(esterurethane)s can be attributed to the higher miscibility of the blocks in the PU with respect to the tri-block copolymer. Moreover, as expected, the values of $\mathrm{T}_{\mathrm{g}}$ for the PCL block are slightly higher 35 for the poly(ester-urethane)s compared with their initial corresponding tri-blocks, thus confirming the contribution of the urethane and hydrogen bonds to the stiffness of the PUs.

SAXS experiments confirmed the phase separated structure of the tri-blocks and the poly(ester-urethane)s. Through the variation of 40 the long period and the relative invariant with temperature, the melting processes of the two blocks has been studied and compared with the results obtained by DSC, showing good agreement obtained with both techniques. In all cases, when all crystals were melted, the copolymers formed a homogeneous 45 melt.

The mechanical properties are well related with the crystalline nature of the poly(ester-urethane)s. In fact, PUs with the amorphous PLLA show the higher elongations at break. Increasing the crystallinity of PLLA-block the materials are more ${ }_{50}$ brittle and reach higher values of the elastic modulus. However, the difficulties with the stoichiometry in the synthesis procedure for the poly(ester-urethane)s obtained from the higher molecular weight tri-block copolymers, can affect dramatically the final molecular weight of the polymer and, consequently, its 55 mechanical properties.

The results of this study demonstrated that the PLLA-b-PCL-bPLLA tri-block copolymers and their corresponding poly(esterurethane)s studied here can be tailored with interesting thermal and mechanical properties and are potential candidates for shape 60 memory materials.

\section{Notes and references}

1 H. Seyednejad, A. H. Ghassemi, C. F. van Nostrum, T. Vermonden and W. E. Hennink, J. Control. Rel., 2011, 152, 168

2 R. Langer, Nature, 1998, 392, 5

653 B. Jeong, Y. H. Bae, D. S. Lee and S.W. Kim, Nature, 1997, 388, 860

4 B. M. Chamberlain, B. A. Jazdzewski, M. Pink, M. A. Hillmyer and W. B. Tolman, Macromolecules, 2000, 33, 3970

5 C. Wischke, A. T. Neffe, S. Steuer and A. Lendlein, J. Control. Rel., 2009, 138, 243

6 S. Neuss, I. Blomenkamp, R. Stainforth, D. Boltersdorf, M. Jansen, N. Butz, A. Perez-Bouza and R. Knuchel, Biomaterials, 2009, 30, 1697

7 A. Lendlein and R. Langer, Science, 2002, 296, 1673

758 R. Auras, B. Harte and S. Selke, J. Appl. Polym. Sci., 2004, 92, 1790

9 D. W. Grijpma and A. J. Pennings, Polym. Bull., 1991, 25, 335

10 G. Maglio, A. Migliozzi and R. Palumbo, Polymer, 2003, 44, 369

11 O. Jeon, S. H. Lee, S. H. Kim, Y. M. Lee and Y. H. Kim, Macromolecules, 2003, 36, 5585

8012 G. Kale, R. Auras and S. P. Singh, J. Polym. Environ., 2006, 14, 317

13 R. V. Castillo, A. J. Müller, J. M. Raquez and P. Dubois, Macromolecules, 2010, 43, 4149

14 L. Peponi, I. Navarro-Baena, J. E. Baez, J. M. Kenny and A. MarcosFernandez, Polymer, 2012, 53, 4561

8515 J. Fernandez, A. Etxeberria and J. R. Sarasua, J. Mech. Behav. Biomed. Mater., 2012, 9, 100

16 D. Cohn and A. F. Salomon, Biomaterials, 2005, 26, 2297 
17 V. Vilay, M. Mariatti, Z. Ahmad, K. Pasomsouk and M. Todo, Mater. Sci. Eng. A, 2010, 527, 6930

18 X. L. Lu, Z. J. Sun, W. Cai and Z. Y. Gao, J. Mater. Med., 2008, 19, 395

519 L. Peponi, I. Navarro-Baena, A. Sonseca, E. Gimenez, A. MarcosFernandez and J.M. Kenny, Eur. Polym. J., 2013, 49, 893

20 M. Bero, J. Kasperczyk and G. Adamus, Macromol. Chem. Phys. 1993, 194, 907

21 G. Kister, G. Cassanas and M. Vert, Polymer, 1998, 39, 267

1022 T. Elzein, M. Nasser-Eddine, C. Delaite, S. Bistac and P. Dumas, J. Coll. Inter. Sci., 2004, 273, 381

23 J. E. Baéz, D. Ramírez, J. L. Valentín and A. Marcos-Fernandez, Macromolecules, 2012, 45, 6966

24 J. Tuominen, J. Kylma and J. Seppala, Polymer, 2002, 43, 3

1525 Y. Kobori, T. Iwata, Y. Doi and H. Abe, Biomacromolecules, 2004, 5,530

26 D. W. Van Krevelen, in Properties of polymers, Elsevier, Amsterdam, 3rd edn., 1990, ch.5

27 J. R. Sarasua, R. E. Prud'homme, M. Wisniewski, A. Le Borgne and

20 N. Spassky, Macromolecules, 1998, 31, 3895

28 A. Sonseca, L. Peponi, O. Sahuquillo, J. M. Kenny and E. Giménez, Polym. Deg. Stab., 2012, 97, 2052

29 L. L. Zhang, C. D. Xiong and X. M. Deng, J. Appl. Polym. Sci., 1995, 56, 103

2530 J. Ahmed, J. X. Zhang, Z. Song and S. K. Varshney, J. Therm. Anal. Calorim. 2009, 95, 957

31 R. V. Castillo and A. J. Müller, Prog. Polym. Sci., 2009, 34, 516

32 I. W. Hamley, P. Parras, V. Castelletto, R. V. Castillo, A. J. Müller, E. Pollet, P. Dubois and C. M. Martin, Macromol. Chem. Phys., $30 \quad 2006,207,941$ 